\title{
Studies on Surface Roughness in Stable and Unstable End-Milling
}

\author{
Mahdi EYNIAN ${ }^{\mathrm{a}, 1}$, Sunday Ogheneochuko USINO ${ }^{\mathrm{a}}$ and Ana Esther BONILLA \\ HERNÁNDEZ ${ }^{\mathrm{b}}$ \\ aUniversity West, Sweden \\ ${ }^{b} G K N$ Aerospace Engine Systems AB, SWEDEN
}

\begin{abstract}
Surface roughness is an important aspect of a machined piece and greatly influences its performance. This paper presents the surface roughness of end-milled aluminium plates in stable and unstable machining conditions at various spindle speed and depth of cuts machined with cylindrical end-mills. The surface roughness is measured using high-resolution surface replicas with a white light interferometry (WLI) microscope. The measurements of the end-milled floors show that the surface roughness as long as the cutting is performed in stable conditions is insensitive to the depth of cut or spindle speed. In contrast, within chattering conditions, which appear according to stability lobes, surface roughness values increase almost $100 \%$. While at the valleys of the stability lobe diagram, there is a gradual increase in roughness, at the peaks of the stability lobe, the transition from the stable to unstable condition occurs with a sudden increase of the roughness values. In the study of down-milled walls, while the roughness increases with the depth of cut within both the stable and the chattering regions, the transition from the stable to chattering condition can lead to a much larger increase in the surface roughness. These results could be used for strategic selection of operation considering the needs of robustness and possible variation of dynamic parameters that can affect the position of the cutting conditions within the stability lobe diagrams.
\end{abstract}

Keywords. chatter, end-milling, white light interferometry, surface roughness

\section{Introduction}

Machining is often used to create fine surfaces with relatively high precision and low roughness. Low surface roughness can improve lubrication, sliding efficiency, wear resistance, fatigue strength, corrosion resistance and aesthetic beauty of a machined part. Several machining parameters, such as cutting speed, spindle speed, depth of cut, feed rate, workpiece material, and cutting tool geometry have significant effects on surface roughness [1]. Notably, self-excited vibration between the tool and the workpiece, known as machining chatter, seriously limits the capability of machining to produce fine surfaces. Chatter itself depends on factors such as cutting force coefficients, which are often higher for stronger materials, and dynamic stiffness between the tool and the workpiece [2]. The dynamic stiffness itself is defined and affected by modal stiffness, natural frequency and damping ratios of vibration modes. The relationships between the cutting conditions, i.e. width of cut, depth of cut and spindle speed are often demonstrated with stability lobe diagrams that could be calculated when cutting force

${ }^{1}$ Corresponding Author. mahdi.eynian@hv.se 
properties, cutting geometry and tool geometry are known and dynamic stiffness of the tool and workpiece are measured by instrumented impact hammer tests $[2,3]$ or identified in-process [4]. While it has been a shared knowledge that machining chatter leads to rougher surfaces, few studies have quantitatively presented the surface roughness as a result of machining chatter. In an early study, Sato et. al. used a light sectioning method to create $2 \mathrm{D}$ roughness maps of surfaces affected by turning chatter [5]. Later works investigated surface roughness in milling. The end-milling process, ignoring the tool's corner radius, creates up to three distinct surfaces, as shown in Figure 1 , which are referred to as "up-milling", "down-milling" walls and "floor surface". The effect of machining chatter on the topography of the machined wall has been simulated by Montgomery and Altintas [6], Heisel et. al [7], Ismail et. al [8] Altintas and Engin [9] and by Seguy et. al [10], but the impact of chatter on floor surface has not been discussed widely. In these papers often a single chatter condition is compared to a single stable condition and the effect of the positioning of a cutting condition with respect to the stability lobe diagrams has not been discussed, thus it is desirable to study how incremental increase of depth of cut or positioning with respect to the stability lobe diagrams affect the surface roughness in a quantitative manner.

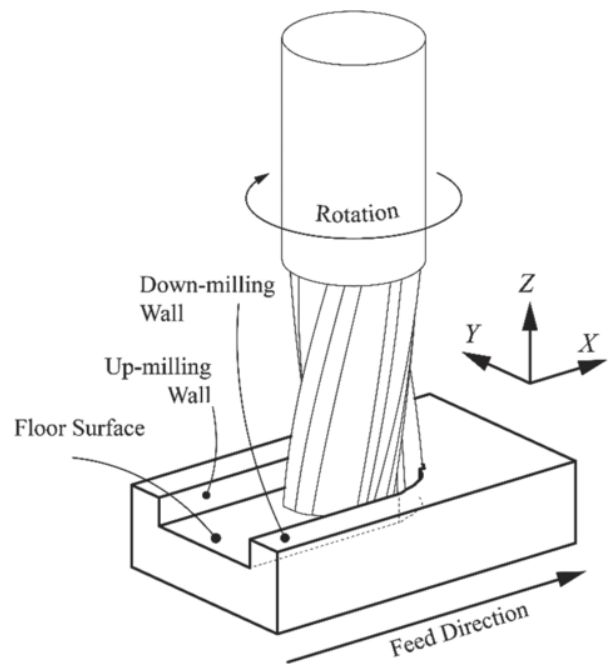

Figure 1. Surfaces created by end-milling

This paper is organized as follows: first, the methods for machining and surface roughness measurement are described. After that, the results of the measurements are presented. The paper is concluded with a discussion of results.

\section{Measurements}

The conditions of cutting tests and surface roughness measurements are described separately. 


\section{Cutting Tests}

In this work, two series of cutting tests are investigated. The information about cutting parameters are listed in Table 1. The workpieces were $35 \mathrm{~mm}$ thick aluminium 7075T651 plates which were machined by a three-axis vertical CNC machine, DMG Mori DMC $635 \mathrm{~V}$ without a cutting fluid (i.e. dry cutting condition). Cutting tools were 3 -flute end-mills with 10 and $20 \mathrm{~mm}$ diameters, from Gühring 3314 series, with $9^{\circ}$ positive radial rake angle $30^{\circ}$ helix angle, that were polished to allow dry cutting with aluminium. Machining tests included removal of the harder surface material by initial machining to a certain depth. The CNC program used for machining was prepared by a Matlab script which created multiple cuts at multiple spindle speeds. Each slot was machined with a certain depth of cut, but the spindle speed was changed after machining a short time interval, this allowed including multiple spindle speeds along the workpiece surface (see Figure 2). Vibration marks could be noted on some combinations of spindle speed and depth of cut as shown in Figure 3.

Table 1. Test Conditions and tool and tool holding details

\begin{tabular}{|c|c|c|c|}
\hline & & Series 1 & Series 2 \\
\hline Tool Dia. & $(\mathrm{mm})$ & 10 & 20 \\
\hline Feed & (mm/tooth) & 0.08 & 0.08 \\
\hline Cutting Speed & $(\mathrm{m} / \mathrm{min})$ & 314-370 & $471-496$ \\
\hline Depth of Cuts (mm) & $(\mathrm{mm})$ & $0.3: 0.05: 1.05$ & $3: 0.2: 6$ \\
\hline Spindle Speed & $(\mathrm{rev} / \mathrm{min})$ & 10000:200:11800 & 7500:100:7900 \\
\hline Holder & & \multicolumn{2}{|c|}{ SPV Spinntec 54807} \\
\hline Sleeve & & SPV Spintec 90110 & Not used \\
\hline Stickout from holder & $(\mathrm{mm})$ & 36.6 & 51.9 \\
\hline
\end{tabular}

a)

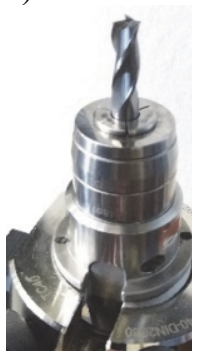

b)

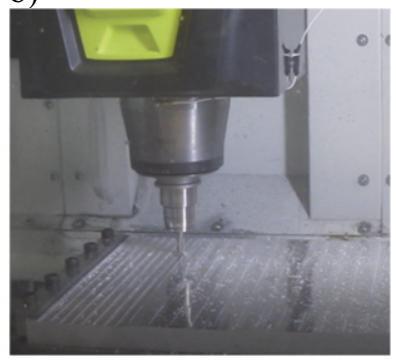

c)

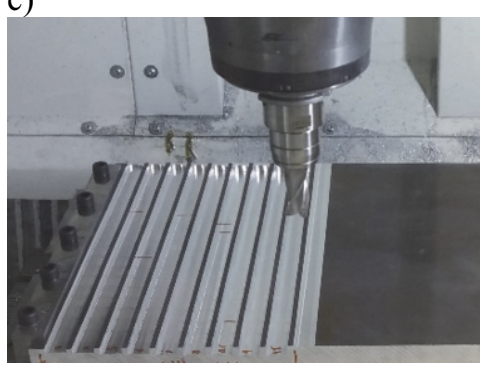

Figure 2.a) $10 \mathrm{~mm}$ tool. b) $10 \mathrm{~mm}$ tool during cutting c) $20 \mathrm{~mm}$ tool during cutting

\subsection{Surface Roughness Measurement}

A white light interferometry (WLI) microscope, Profilm 3D from Filmetrics (Figure 4), was used for the measurement of surface topography. 


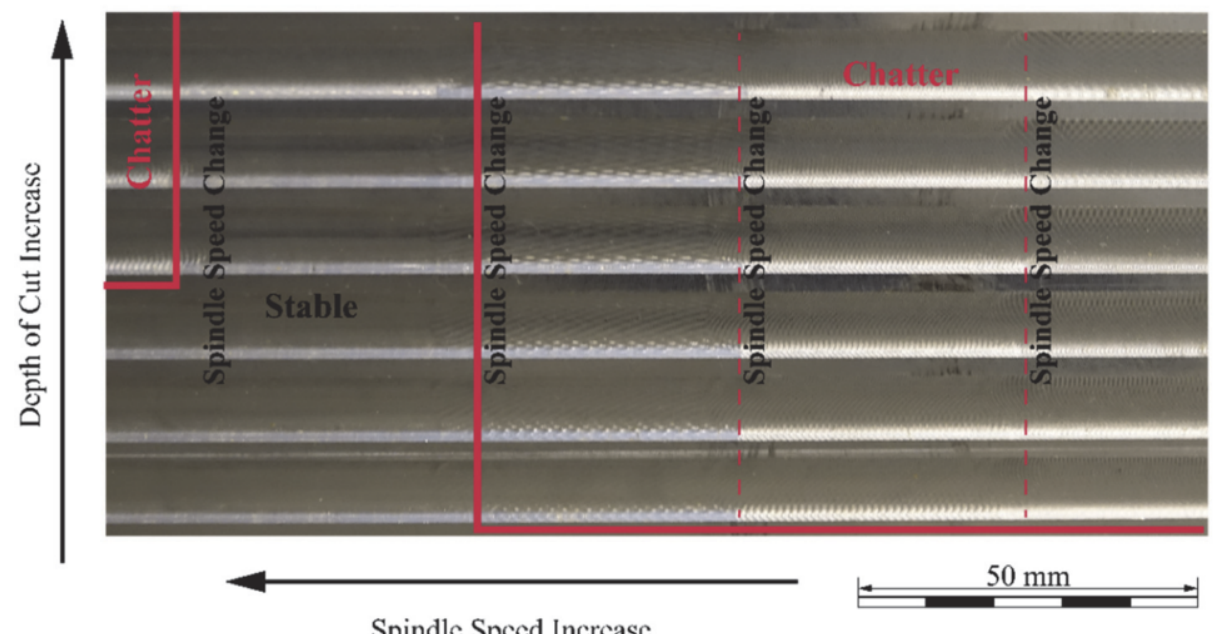

Figure 3. End milled floor surface Conditions, series S1. Note the difference in surface appearance by changing spindle speed and depth of cut. Spacings between machined slots are $3 \mathrm{~mm}$ wide.

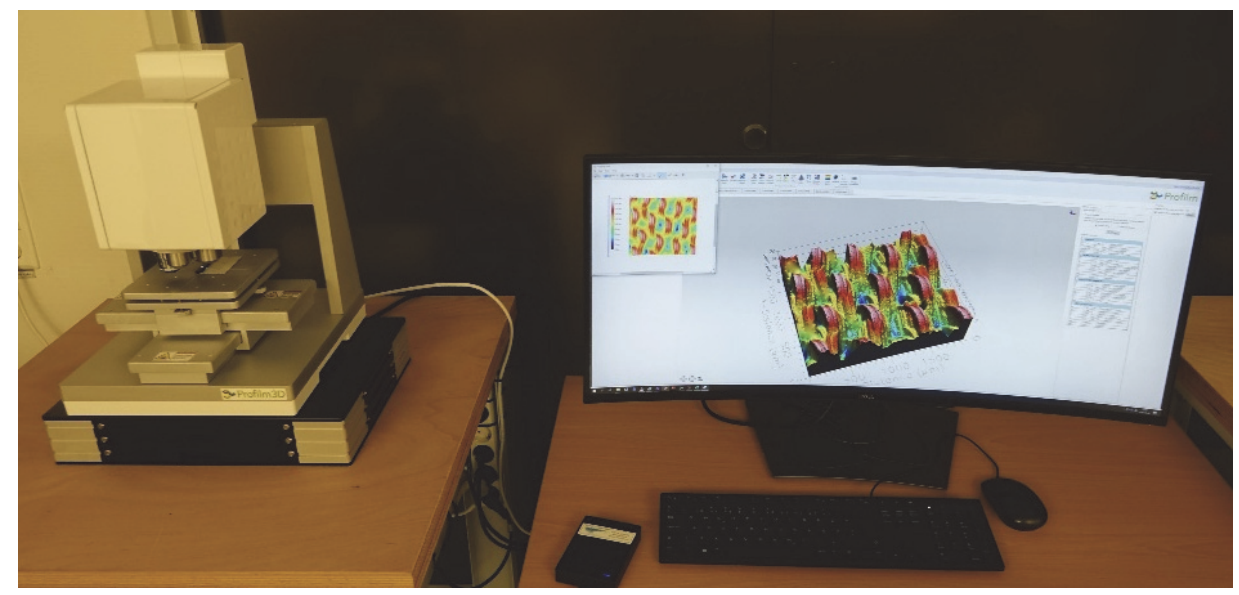

Figure 4. WLI microscope system

Due to the size and weight limitations of the microscope table, surface replicas were made using a replicating silicone compound as shown in Figure 5. The replicas were carefully labelled before measurement and storage. Surfaces from smaller machined samples in stable and chattering conditions were also measured directly and with replication, which showed $0.02 \mu \mathrm{m}$ and $0.12 \mu \mathrm{m}$ difference of Sz value between the direct and replica measurements for stable and chatter conditions respectively.

Surface roughness measurements were carried out on each combination of spindle speed and depth of cut along the middle line of the each generated replica. The measured points were then levelled, outliers were removed and the area roughness was calculated which was then entered into an excel sheet. Since the field of view of the microscope was limited $(2.0 \times 1.7 \mathrm{~mm}$ with $10 \mathrm{X}$ objective $)$, four measurements were made from the replica for each cutting condition and an average $\mathrm{Sz}$ value and its standard deviation are 
calculated and entered to a table for comparison across all depth of cut-spindle speed combinations. Sz, as defined in ISO 25178-2:2012 2, is the maximum height from the highest point to the deepest valley.

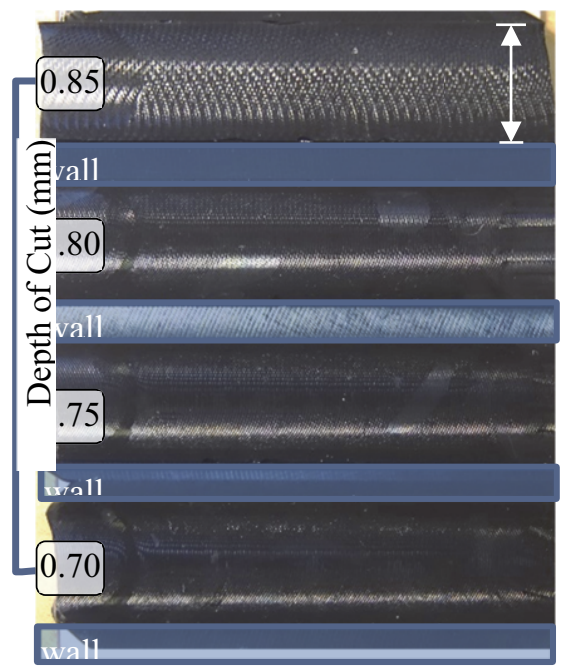

Figure 5. a resin surface replica, depicting the depth of cuts of $0.70,0.75,0.80$ and $0.85 \mathrm{~mm}$ (ordered from bottom to top), at the spindle speed of $11400 \mathrm{rev} / \mathrm{min}$. The chatter marks on $0.85 \mathrm{~mm}$ depth of cut are noticeable by the naked eye.

As shown in Figure 3 and Figure 5, the chatter marks are perceptible by the naked eye. The perceivable chatter/stable machining conditions were also noted in an excel file for comparison to the surface roughness measurements.

\section{Results}

\subsection{Floor Surface}

A measurement from a stable condition is compared to a measurement from an unstable condition in Figure 6. As shown in Figure 6a, the surface texture in stable cutting is dominated by narrow valleys spaced at about $240 \mu \mathrm{m}$, which is equal to the feed per revolution (see Table 1); which shows that these valleys are made by one of the cutting edges that has a closer axial positioning to the workpiece. The tail movement of the same edge removes material also in its back movement as shown by the arcs in the opposite direction to the feed direction, but missing rhombus-like lands of about $8 \mu \mathrm{m}$ height. These peaks determine the Sz value of the surface. The back cutting is affected by the orientation of the axis of rotation of the spindle with respect to the feed direction [11].

For machining in chatter condition (Figure 6b), the surface is dominated by valleys and peaks at about twice the feed/rev $(480 \mu \mathrm{m})$. A notable axial movement, with a wavelength of approximately $1 \mathrm{~mm}$, leads to a notable Sz roughness value of $19 \mu \mathrm{m}$. This shows that while the chatter of cylindrical end-mills is strongly affected by the vibrations between the tool and workpiece in feed and crossfeed directions (X, and $\mathrm{Y}$, 
see Figure 1), a notable movement also happens between the tool and workpiece, at the axial (or surface normal direction), $\mathrm{Z}$.

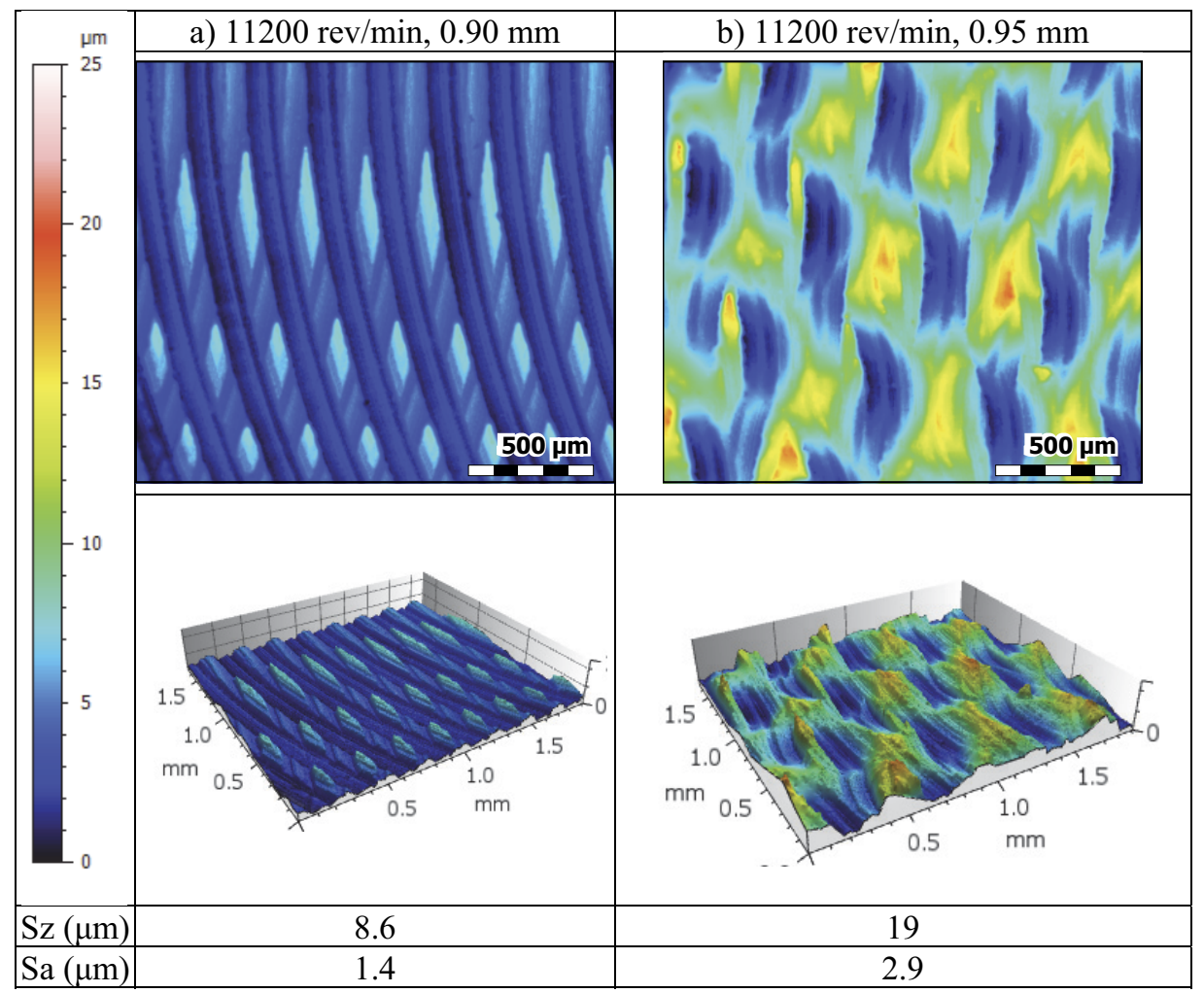

Figure 6. Cut floor roughness, a) stable cut, b) chatter

The $S z$ surface roughness values (average from four positions for each combination of spindle speed and depth of cut) according to ISO 25178-2:2012 are shown in Figure 7. Increasing depth of cut and spindle speed in the stable region does not affect this roughness in a notable trend, and the $S z$ remains 8-9 $\mu \mathrm{m}$ as shown in Figure 7. In contrast, increasing the depth of cut in the unstable region almost always increases the surface roughness. Crossing from the stable to unstable region, at valleys of the stability lobe (10600-10800 rev/min) and $11800 \mathrm{rev} / \mathrm{min}$ does not lead to a sudden increase of roughness, but close to the peaks of the stability lobes, at $10000 \mathrm{rev} / \mathrm{min}$ and 11200 $\mathrm{rev} / \mathrm{min}$ a sharp increase in surface roughness happens. Within the chatter region, the surface roughness values with respect to the spindle speed are highest on the top of stability lobe peaks (10 000 and $11200 \mathrm{rev} / \mathrm{min}$ ), with values of 18.5 and $19.5 \mu \mathrm{m}$ respectively, but they reduce as spindle speed increases until the next stability lobe peak is reached. 


\begin{tabular}{|c|c|c|c|c|c|c|c|c|c|c|}
\hline & \multicolumn{5}{|c|}{ Chatter Boundary (Ocular) } & \multicolumn{2}{|c|}{8.4} & \multicolumn{2}{|c|}{$S_{\mathrm{Z}}(\mu \mathrm{m})$} & 19.5 \\
\hline \multirow{3}{*}{1.0} & 18.5 & 18.3 & 15.9 & 13.1 & 12.4 & 11.9 & 19.5 & 17.8 & 15.1 & 14.4 \\
\hline & 17.8 & 17.7 & 15.4 & 12.8 & 12.7 & 11.8 & 19.3 & 17.8 & 14.7 & 14.4 \\
\hline & 18.3 & 17.5 & 15.3 & 12.8 & 12.4 & 11.4 & 19.0 & 17.3 & 14.5 & 14.1 \\
\hline 0.9 & 11.3 & 17.2 & 15.4 & 12.7 & 12.7 & 11.2 & 8.9 & 17.6 & 13.9 & 14.9 \\
\hline \multirow{3}{*}{0.8} & 10.5 & 17.7 & 14.5 & 12.7 & 12.0 & 11.3 & 8.8 & 17.3 & 13.9 & 13.8 \\
\hline & 10.0 & 17.1 & 14.0 & 12.5 & 12.3 & 11.3 & 8.7 & 9.2 & 11.9 & 13.8 \\
\hline & 9.4 & 17.1 & 13.7 & 12.3 & 11.8 & 11.2 & 8.5 & 8.9 & 13.5 & 14.7 \\
\hline \multirow{2}{*}{0.7} & 9.7 & 9.6 & 13.1 & 12.2 & 12.6 & 10.6 & 8.7 & 9.0 & 12.1 & 13.3 \\
\hline & 9.2 & 9.3 & 13.4 & 12.2 & 12.7 & 10.3 & 8.7 & 11.2 & 14.3 & 13.9 \\
\hline \multirow[t]{2}{*}{0.6} & 9.6 & 8.9 & 9.5 & 11.7 & 11.5 & 9.8 & 8.7 & 10.0 & 14.2 & 13.5 \\
\hline & 9.4 & 9.5 & 8.9 & 11.6 & 11.4 & 9.7 & 8.8 & 9.1 & 12.5 & 12.7 \\
\hline \multirow[t]{2}{*}{0.5} & 9.5 & 9.2 & 8.7 & 11.5 & 11.9 & 9.5 & 8.6 & 9.5 & 12.2 & 12.5 \\
\hline & 10.3 & 8.9 & 9.1 & 11.8 & 10.6 & 10.1 & 8.3 & 8.5 & 8.4 & 12.3 \\
\hline \multirow[t]{2}{*}{0.4} & 9.3 & 9.4 & 9.3 & 11.3 & 9.9 & 9.6 & 8.8 & 8.8 & 9.0 & 11.5 \\
\hline & 9.5 & 9.2 & 9.4 & 10.1 & 10.0 & 8.7 & 9.1 & 9.3 & 8.6 & 9.4 \\
\hline \multirow[t]{2}{*}{0.3} & 9.8 & 9.1 & 9.3 & 9.0 & 9.0 & 8.6 & 8.2 & 9.1 & 9.0 & 8.5 \\
\hline & 10000 & & 10400 & & $\begin{array}{l}0800 \\
\text { Spe }\end{array}$ & & $\begin{array}{l}1120 \\
\min )\end{array}$ & & 1160 & \\
\hline
\end{tabular}

Figure 7. $S z$ Surface roughness values for floor surface of end-milled slots on aluminium plate, spindle speed $10000-11800 \mathrm{rev} / \mathrm{min}$ and depth of cut $0.30-1.05 \mathrm{~mm}$

\subsection{Wall Surface.}

The wall roughness was studied for series 2 , with a tool diameter of $20 \mathrm{~mm}$ that allowed stable and chattering cuts with higher depth of cuts. The surface condition on downmilling wall (see Figure 1) is shown in

Figure 8 for a depth of cut of $5.8 \mathrm{~mm}$, at spindle speeds from $7500-7900 \mathrm{rev} / \mathrm{min}$. At this depth of cut, the machining is stable only at $7600 \mathrm{rev} / \mathrm{min}$, leaving a surface with $\mathrm{Sz}$ value of $5.6 \mu \mathrm{m}$, but other depth of cuts, (even at lower spindle speed of $7500 \mathrm{rev} / \mathrm{min}$ ) lead to roughness values ranging from $17.2 \mu \mathrm{m}$ to $29.9 \mu \mathrm{m}$, equivalent to $3-5$ times increase in roughness. This represents strong movements of the cutting tool even in the wall direction during cutting. The ridges and valleys are oriented at an angle corresponding to the helix angle of the tool $\left(30^{\circ}\right)$ for the spindle speeds of 7500,7700 and $7800 \mathrm{rev} / \mathrm{min}$. Considering the feed/tooth of $80 \mu \mathrm{m}$, corresponding to the feed per revolution of $240 \mu \mathrm{m}$, the ridges and valleys are spaced approximately twice of the feed per revolution, i.e. $480 \mu \mathrm{m}$.

Wall conditions at combinations of the depth of cut and spindle speed (7500-7900 $\mathrm{rev} / \mathrm{min}, 3-6 \mathrm{~mm}$ depth of cut) are also measured with a $50 \mathrm{X}$ objective with a field of view of $400 \times 340 \mu \mathrm{m}$ and reported in Figure 9. Due to the limited field of view, in comparison of spacing between features found in

Figure 8, these measurements should be treated with caution, however, it can be seen that the roughness in stable conditions is rather independent of spindle speed, and it increases slightly with the depth of cut. Within the unstable region also the roughness increase with increasing depth of cut, with few exceptions, such as spindle speed of 7900 at depth of cut of $3.8 \mathrm{~mm}$. However, unlike the floor surface of series 1 , the roughness is high even to the left of the stability lobe peak, (at the spindle speed of $7600 \mathrm{rev} / \mathrm{min}$ ). 


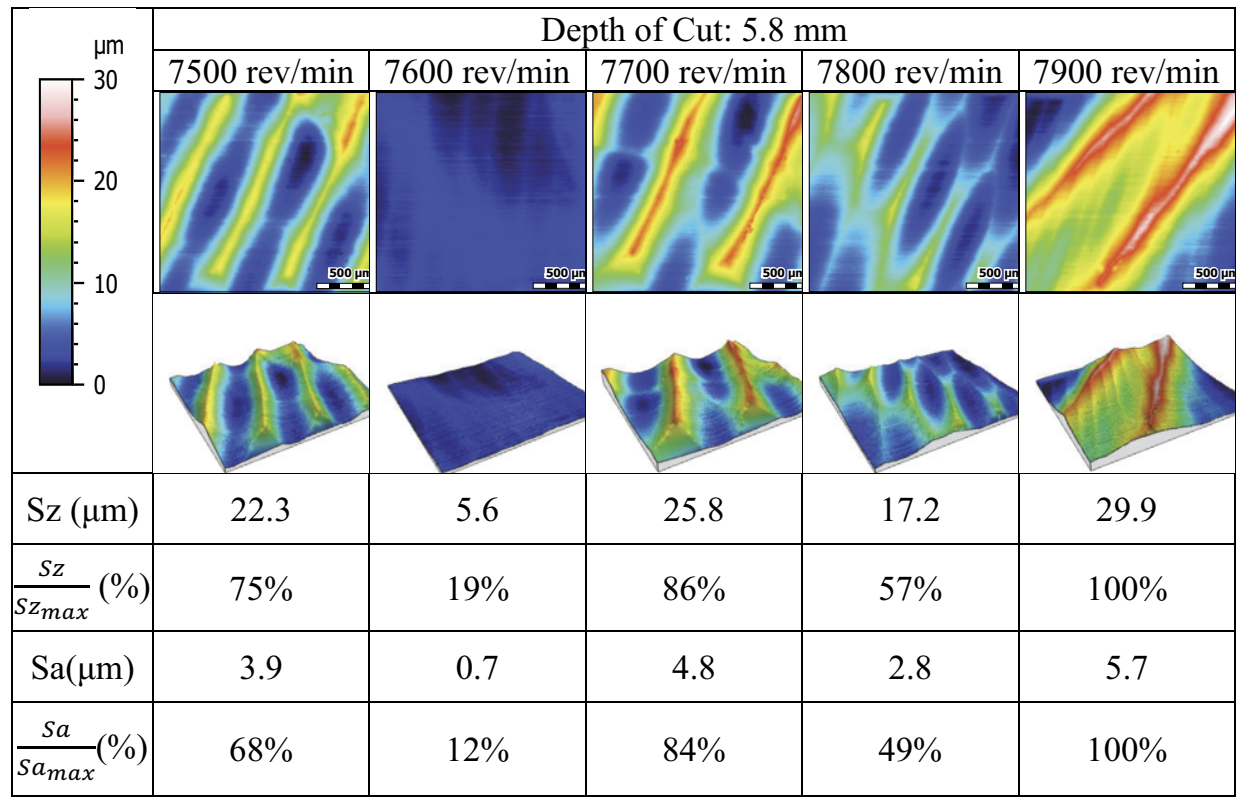

Figure 8. Roughness on down-milling wall, machining with $20 \mathrm{~mm}$ tool.

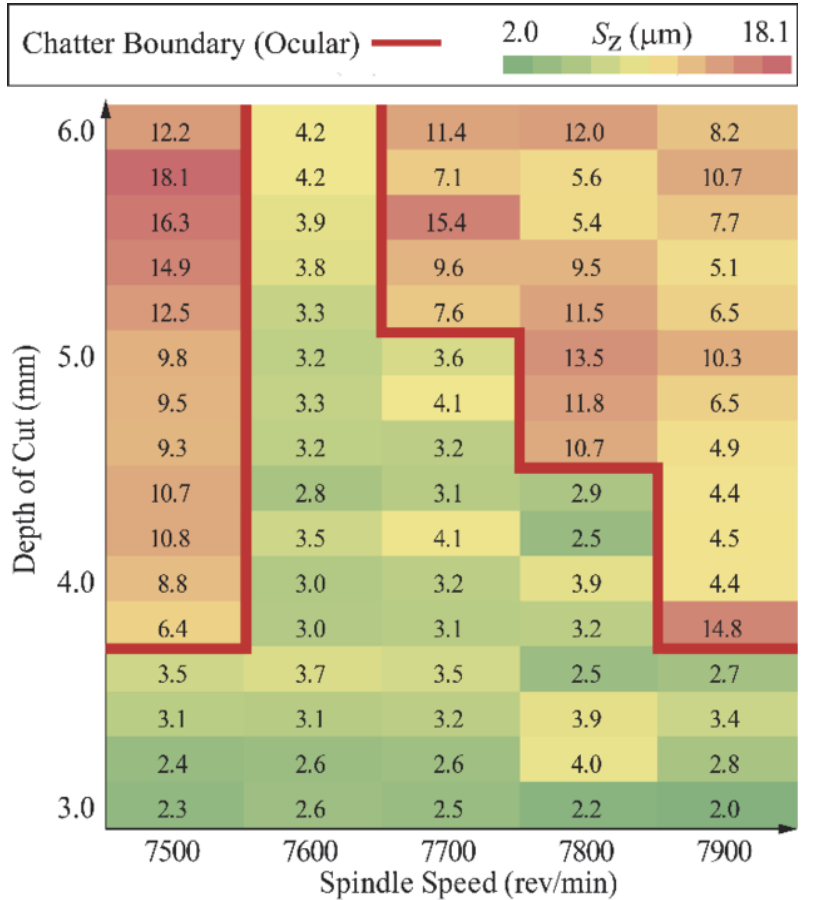

Figure 9. Surface Roughness on Down-milling wall, slot milling with $20 \mathrm{~mm}$ tool 


\section{Conclusion}

The floor roughness for stable cutting conditions is controlled mainly by inaccuracies in the cutter's manufacturing, mounting and also the perpendicularity error of the spindle's rotation axis with respect to the table and feed direction. This makes the floor roughness rather independent of the depth of cut or spindle speed in stable cutting conditions; while the surface roughness values in chattering conditions are highly affected by the position of the cutting condition combination in with respect to the stability lobes. Just above the peaks of the stability lobes, with a sharp increase, very high values for the surface roughness values are measured, while at the valleys of the stability lobe diagram, the transition from the stable to chatter condition is rather soft.

In terms of wall roughness, 3-5 times higher roughness values are found within the chattering region compared to the stable region. Increasing depth of cut often increases the roughness even in the stable cutting conditions; however, unlike the floor roughness which was strongly affected by the positioning with respect to the lobes, no notable trend in terms of the effect of spindle speed on surface roughness in chattering conditions could be found.

The present study was limited to cylindrical tools with rather sharp corners. This study could be continued for other tool geometries, particularly insert cutters with large corner radius, ball end mills and barrel type tools. Furthermore, in this study, the chatter was a result of high-frequency (i.e. above $1000 \mathrm{~Hz}$ ) vibrations from tool modes.

In this paper, in the depth of cut-spindle speed charts, the Sz parameter has been depicted. Since this parameter is controlled by the height of a few points on the measurement range, it may be more suitable to consider a parameter such as Sa that takes contribution from all of the measured points.

\section{Acknowledgement}

The machining tests reported in this work were done under the KKS Hög project Drn. 2015/796. Surface measurement was done as a master's thesis at University West with the help of the KKS-Primus RFMMT project. Cutting tests were performed with the help of research engineer Andreas Gustafsson who selected the tooling systems, contributed to the selection of the cutting conditions and operated the machine tool.

\section{References}

[1] M.P. Groover, Fundamentals of modern manufacturing: materials processes, and systems, John Wiley \& Sons, 2007.

[2] Y. Altintaş, E. Budak, Analytical prediction of stability lobes in milling, CIRP Annals-Manufacturing Technology, 44 (1995) 357-362.

[3] E. Budak, Y. Altintas, Analytical prediction of chatter stability in milling — part I: general formulation, Journal of Dynamic Systems, Measurement, and Control, 120 (1998) 22-30.

[4] M. Eynian, In-process identification of modal parameters using dimensionless relationships in milling chatter, International Journal of Machine Tools and Manufacture, 143 (2019) 49-62.

[5] H. Sato, M. O-hori, H. Tsuwa, Characteristics of two dimensional surface roughness - taking selfexcited chatter marks as objective, CIRP Annals, 30 (1981) 481-486.

[6] D. Montgomery, Y. Altintas, Mechanism of cutting force and surface generation in dynamic milling, Journal of engineering for industry, 113 (1991) 160-168. 
[7] U. Heisel, J. Milberg, Vibrations and surface generation in slab milling, CIRP annals, 43 (1994) 337 340.

[8] F. Ismail, M. Elbestawi, R. Du, K. Urbasik, Generation of milled surfaces including tool dynamics and wear, Journal of Engineering for Industry, 115 (1993) 245-252.

[9] Y. Altintas, S. Engin, Generalized modeling of mechanics and dynamics of milling cutters, CIRP Annals, 50 (2001) 25-30.

[10] S. Seguy, G. Dessein, L. Arnaud, Surface roughness variation of thin wall milling, related to modal interactions, International Journal of Machine Tools and Manufacture, 48 (2008) 261-274.

[11] P. Franco, M. Estrems, F. Faura, A study of back cutting surface finish from tool errors and machine tool deviations during face milling, International Journal of Machine Tools and Manufacture, 48 (2008) 112-123. 